\title{
Car-drivers' Knowledge and Practices Regarding First Aid Of Road Traffic Accidents at Sohag University
}

\author{
Asmaa. M. Madkour ${ }^{1}$, Safaa A.M. Kotb ${ }^{2}$, Safaa. R. Mahmoud ${ }^{3} \&$ Thorea.A. Mahmoud $^{4}$ \\ 1. Assistant lecturer in family and Community Health Nursing- Faculty of Nursing- Sohag University, Egypt. \\ 2. Professor of family and Community Health Nursing- Faculty of Nursing- Assuit University. Egypt. \\ 3. Assistant Professor of family and Community Health Nursing, Faculty of Nursing, Assuit Universit, Egypt. \\ 4. Lecturer of family and Community Health Nursing-Faculty of Nursing- Sohag University, Egypt.
}

\begin{abstract}
Road traffic accidents have been responsible for an increasing number of deaths and disabilities worldwide. Aim: Assess knowledge and practice of car drivers regarding first aid of road traffic accident. Subjects and methods: A cross-sectional research design was used in the study. It was conducted at Sohag University. A 87 Car drivers was participated in this study. Two tools developed by the researcher were used: Tool:the first tool: A structured interviewing questionnaire that include two parts; Part 1: demographic data of car drivers. Part 2: knowledge assessment questionnaire about first aid and road traffic accidents. Second tool: An observational checklist was used to assess practices of drivers regarding first aid of road traffic accidents. Results: The mean age of the participants was $43.36 \pm 9.48 .33 .3 \%$ of them had secondary education. $92.0 \%$ of them weren't having previous first aid training. $86 \%$ of them had an unsatisfactory knowledge level and all of studied car drivers had unsatisfactory practices of first aid of road traffic accident. Conclusion: The current study concluded that the majority of them had an unsatisfactory knowledge level and total of car drivers had unsatisfactory practices of first aid of road traffic accident Recommendations: Design and implement training programs for car drivers regarding first aid of road traffic accidents.
\end{abstract}

Keywords: Car-Driver \& Road Traffic First Aid Accidents.

\section{Introduction}

Accident is an unplanned process of events that leads to undesired injury, loss of life and damage to the system or the environment. It's a part of the price people pay for technological progress and are no longer considered accidental, because majority of them are preventable (Centers for Diseases Control \& Prevention CDCP, 2017).

Road traffic accident and injuries have become a burden worldwide. The World Health Organizations global report on road traffic safety, more than 1.25 million people die each year as a result of road traffic crashes. Road traffic accident are the second leading cause of death for people between the ages of 5 and 29 and third leading cause for people between 30 and 44. With the number of vehicles rapidly rising in developing countries, this epidemic is quickly worsening in low and middle income countries and is on its way to becoming the third leading cause of death and disabilities by the year 2020. (World Health Organization WHO, 2016 )

A road traffic accident is a collision between vehicles, vehicles and pedestrians, vehicles and animals, vehicles and geographical or architectural obstacles.
The most common kinds of collision are vehicle rear end collisions, side impact collisions, vehicle rollover, head-on collisions, single car accidents and multiple vehicle pileups (Gupta et al., 2014 \& Baburao \& Gbadamosi, 2016).

Road traffic accidents occur due to excessive speed, defective roads, poor street lighting, defective layout of cross roads and speed breakers, defective vehicles, disregard of road signs, fatigue, alcoholism and unusual behaviors of men and animals ( Kussia, 2017).

First aid includes a set of actions performed for an injured person or a person suffering a sudden illness in sake of saving patient life by maintaining basic vital signs in optimal condition until the arrival of advance medical care .Rescuing a victim of road traffic accident is not limited to providing a proper first aid, it also includes calling the ambulance to provide the advanced management. Providing first aid for car crash victims is very important to avoid irreversible brain damage caused by hypoxia which may ensue in a short time, i.e. 4-5 minutes ( Karyś et al., 2015). 
Participants of road traffic are at risk of accidents; therefore, each driver should know how to administer first aid to minimize health consequences of road traffic accidents, if need be.The extent of this phenomenon necessitates mastering the principles of first aid, particularly among drivers. (Awasthi et al., 2018)

Nurses can play a vital role in assessment car drivers' knowledge and practices regrading first aid of road traffic accidents as component of first aid, sign and management of respiratory problem, management of bleeding and bone fracture victim, position of the victim during road traffic accident, transportation of victim, a trend of road traffic accident and what action was taken during victim with respiratory problem, heavy bleeding and neck injury and bone fracture.( Olumide et al., 2015)

Nurses can play a major role in prevention of road accident by educate the families and communities. they can identify risk factors of road accident through assessing the accident environment and help to decrease the number and severity of these accidents through anticipatory guidance, environmental modification and safety education. (Magruder et al., 2016 \& Stanhope \& lancasters, 2018)

\section{Significance of the study}

According to a Central Agency for Public Mobilization and Statistics report that car accidents have 23.6 percent in 2019 to reach 8,480 accidents, resulting in 3,087 people death, 11,803 injured and 13,441 vehicles damaged. Sixty percent of all road traffic deaths have occurred on the road before arriving to the hospital.It has been found that prompt and appropriate first aid can prevent deaths by $39 \%$ and the severe consequence of injuries if it is introduced immediately and effectively to Road traffic accident casualty before the arrival of the emergency services. Different studies have supported the idea that lay person should participate in rescuing road traffic accident victims (, Khader et al., 2017 \& Central agency for puplic moblization and statistics capmas, 2019). So the researcher assessed the car drivers, knowledge and practices regarding to first aid of road traffic accidents

\section{Aim of study}

1- Assess knowledge of car- drivers regarding to first aid of road traffic accidents.

2- Assess practice of car- drivers regarding to first aid of road traffic accidents.

\section{Research question}

1- What is the level of car drivers' knowledge regarding to first aid of road traffic accidents?

2- Do drivers' practices sufficient to deal with road traffic accident?

\section{Subject \& Methods}

Research design

Across-sectional research design was used in this study.

Setting

The study was conducted in the four cars'units that presented in sohag university such as old sohag university, new sohag university hospital, faculty of medicine and faculty of agriculture.

\section{Sample}

87 car drivers who working at Sohag University were including in the study and they are agree to participate in the study.

Tools of the study

Two tools were developed by the researcher to collect necessary data after review of current related literature design in simple Arabic language; included a structured interview questionnaire and observational checklist.

Tool I: A structured interviewing questionnaire It consisted of two parts:

First part: Assess demographic data for car drivers. This part is composed of a closed/ended question as age, education, residence, marital status and years of experience, history of previous first aid training , history of previous witness road traffic accident and Previous assisting in road traffic accident victims.

Second part: -Assess knowledge of car drivers regarding road traffic accidents and first aid. It includes (35) questions, such as assess knowledge about road traffic accidents. It contains of (4) questions as definition, types, causes and Risks from road traffic accidents.

- Assess knowledge about first aid.It consist of (4) questions as definition, importance, principles, and components of first aid kit.

- Assess knowledge about cardiac and breathing arrest. It includes (4) questions as definition, causes, signs of cardiac arrest and the definition of cardiopulmonary resuscitations.

- Assess knowledge about shock. It contains (3) questions as definition, causes and signs and symptoms of shock.

- Assess knowledge about wound and bleeding. It includes (7) questions as definition, types, examples of open and closed wound, definition, types of bleeding and examples of external bleeding.

- Assess knowledge about burns. it consists of (7) questions as definition of burn, definitions and characteristics of first degree, second degree of burn and third degree of burn.

- Assess knowledge about fractures. it includes (6) questions as definition, types, characteristics of simple, complicated, compound and signs of fracture. 


\section{Scoring system}

For the knowledge one degree for each correct answer, zero degree for the incorrect one and do not know. For each part, the scores of the items were summed up and converted into a percentage.The driver's knowledge was considered satisfactory if $50 \%$ and more, unsatisfactory if percent score was less than 50\% (EL-Sharkasy et al., 2015)

\section{Second tool: An observational checklist}

It was developed by the researcher and used to assess practice of car drivers about first aids measures such as cardiopulmonary resuscitations (14) steps, wound and bleeding (15) steps, shock (6) steps, fracture (12) steps and burns(9) steps.

\section{Scoring system}

In the observational checklists, items "done" take one grade and "not done " take zero grade. for each step , the scores of items were summed up and the total was divided by the number of the items, giving a mean score for the part. These score were converted into a percent score . the performance was considered Satisfactory if the percent score was $60 \%$ or more and unsatisfactory if it less than 60\%.( El-sayed, 2018).

Validity of tools: It was checked and revised by panel of seven experts from community health nursing and medical surgical nursing at assuit and sohag university to review the instrument for clarity , relevance, comprehensiveness, understanding and applicability. According to their opinion minor modifications such as( observational checklists of cardioplumonary rescustations and burns) were applied.

Reliability test was carried out by the researcher in order to examine the internal consistency of its questions. it was done during the pilot study before starting of data collected on $10 \%$ (9) car drivers. The value of cronbach's alpha for knowledge 0.788 and 0 . 721 for practice implying that the instrument was consistent and reliable in achieving.

\section{Methodology : Administrative phase}

An official approval letter was obtained from the Dean of the faculty of Nursing to president of Sohag University to conduct the study after full explanation about the aim of the study. This letters included a permission to carry out the study.

\section{Pilot study}

A pilot study that included (9) car drivers (10\%) was carried out to ensure clarity and applicability of the developed tool and to estimate the time needed to fill the questionnaire's. This sample was included in the total study sample and the final forms of the tools were developed .

Data collection phase:

\section{Ethical consideration}

The researcher followed all ethical issues in conducting the research. Consent was secured orally from the participants. The participants were informed that participation in this study is voluntary ;they can withdraw at any time during the study without giving reasons .The researcher have explained the aim of the study to all schools students in the study sample. They assured that any obtained information would be strictly confidential.

\section{Field work}

An official letter approval was obtained from president of Sohag University and directorate of cars unit in sohage university to obtain necessary approval to conduct the study. This letter included apermission to collect the necessary data and explain the purpose and nature of the study. Each car driver was informed about the purpose and nature of the study in a special room at car unit.

Data collection for this study was carried out at a period of six months from beginning of January till the end of June 2019, two days per week (Sunday and Wednesday), 10-11 car-drivers per day. Oral consent was obtained from every participant who accepts to participate in the study, confidentiality of data were assured. The questionnaire was filled by the researcher from each driver after full explanation; it took about 20-30minutes.

\section{Statistical Analysis}

Data entry and data analysis were done using SPSS version 19 (Statistical Package for Social Science). Data were presented as number, percentage, mean, standard deviation. Chi-square test was used to compare between qualitative variables. P-value considered statistically significant when $\mathrm{P}<0.05$. 


\section{Results}

Table (1): Distribution of the car drivers according to their personal characteristics, at Sohag University, (N=87), 2019.

\begin{tabular}{|c|c|c|}
\hline Items & No. (87) & $\overline{\%}$ \\
\hline \multicolumn{3}{|l|}{ Age: (years) } \\
\hline $30-39$ & 35 & 40.2 \\
\hline $40-49$ & 26 & 29.9 \\
\hline 50 or more & 26 & 29.9 \\
\hline Mean \pm SD (Range) & \multicolumn{2}{|c|}{$43.36 \pm 9.48(28.0-59.0)$} \\
\hline \multicolumn{3}{|l|}{ Residence: } \\
\hline Rural & 51 & 58.6 \\
\hline Urban & 36 & 41.4 \\
\hline \multicolumn{3}{|l|}{ Educational level } \\
\hline Read and write & 19 & 21.8 \\
\hline Primary & 16 & 18.4 \\
\hline Preparatory & 23 & 26.4 \\
\hline Secondary & 29 & 33.3 \\
\hline \multicolumn{3}{|l|}{ Marital status } \\
\hline Single & 12 & 13.8 \\
\hline Married & 73 & 83.9 \\
\hline Widowed & 2 & 2.3 \\
\hline \multicolumn{3}{|l|}{ Years of experience } \\
\hline $5-<10$ & 11 & 12.6 \\
\hline $10-<15$ & 20 & 23.0 \\
\hline $15-<20$ & 14 & 16.1 \\
\hline$\geq 20$ & 42 & 48.3 \\
\hline Mean \pm SD (Range) & \multicolumn{2}{|c|}{$19.54 \pm 8.72(5.0-38.0)$} \\
\hline \multicolumn{3}{|l|}{ First aid training } \\
\hline Yes & 7 & 8.0 \\
\hline No & 80 & 92.0 \\
\hline \multicolumn{3}{|c|}{ Previous witness of road accident } \\
\hline Yes & 81 & 93.1 \\
\hline No & 6 & 6.9 \\
\hline \multicolumn{3}{|c|}{ Previous assisting in road accident } \\
\hline Yes & 48 & 59.3 \\
\hline No & 33 & 40.7 \\
\hline
\end{tabular}

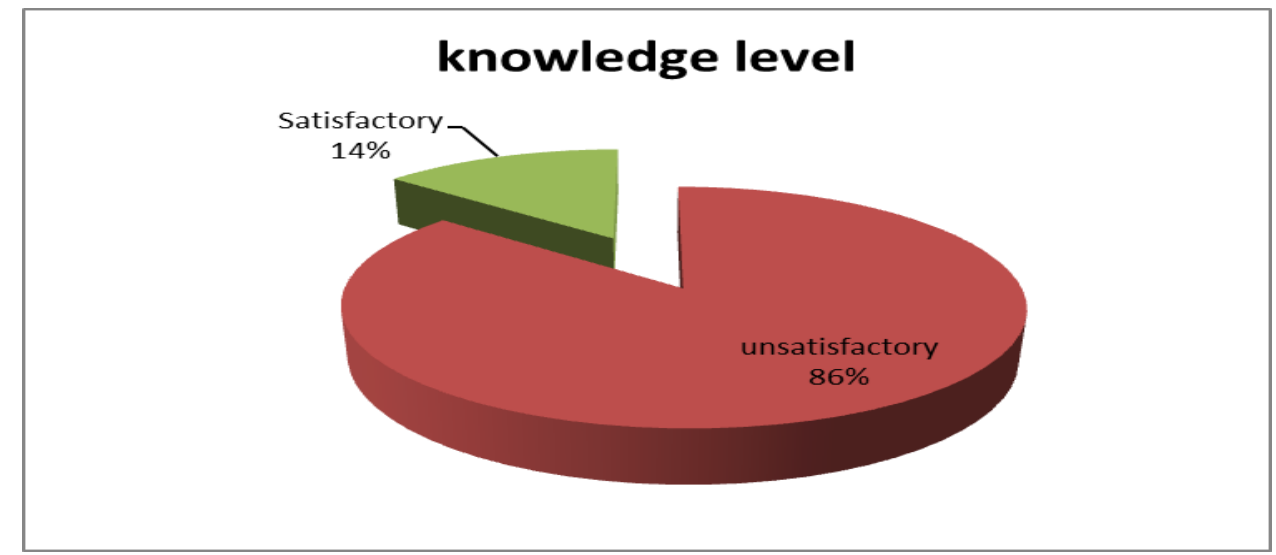

Figure (1): Knowledge level of the car drivers about road traffic accident, at Sohag University, 2019, (N=87).

Table (2): Distribution of the car drivers, according to their level of practice, at Sohag University, (N=87), 2019.

\begin{tabular}{|l|c|c|}
\hline Practical level & No. $(\mathbf{n}=\mathbf{8 7})$ & \% \\
\hline unsatisfactory & 87 & 100.0 \\
\hline Satisfactory & 0 & 0.0 \\
\hline
\end{tabular}




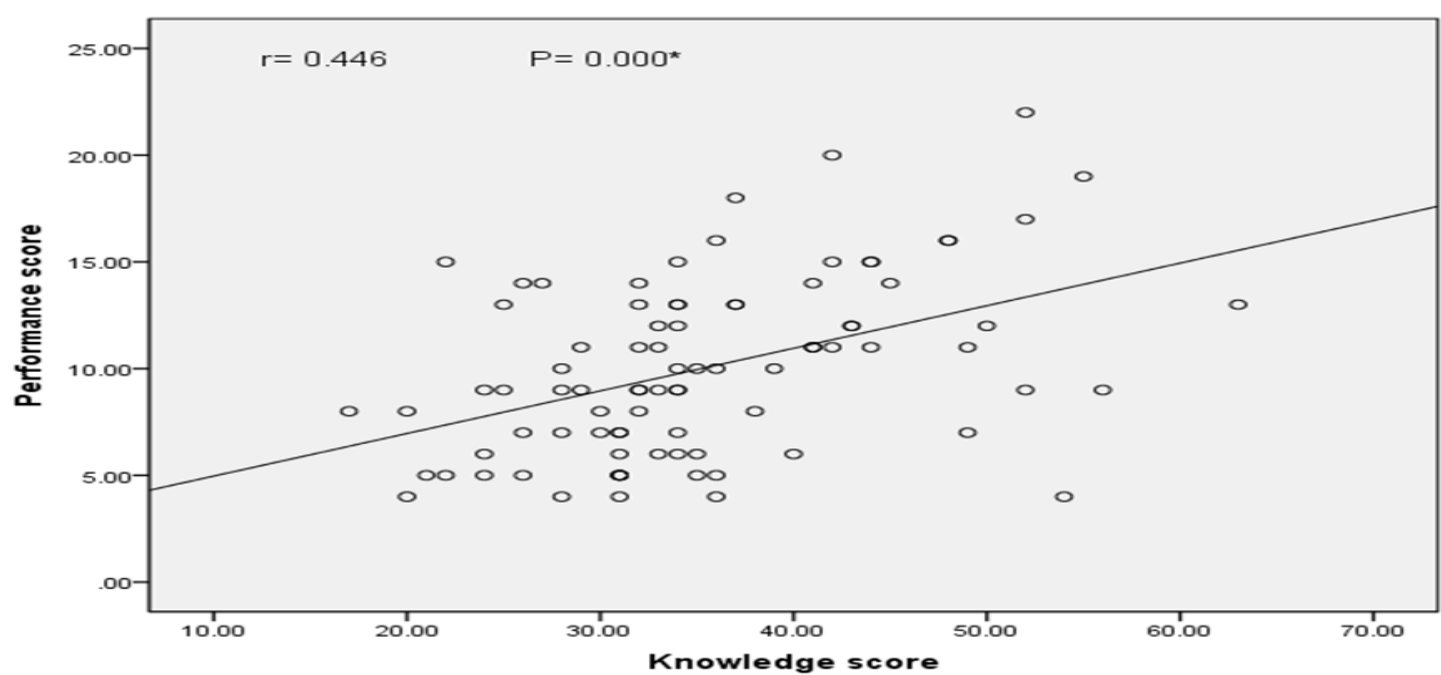

Figure(2): Correlation between knowledge and performance score of car drivers regrading first aid about road accident, at Sohag University, (N=87), 2019.

Table (3): Relationship between car drivers score of knowledge and their personal characteristics, at Sohag University, (N=87), 2019.

\begin{tabular}{|c|c|c|}
\hline \multirow{2}{*}{ personal characteristics } & Knowledge score & \multirow{2}{*}{ P-value } \\
\hline & Mean \pm SD & \\
\hline Age: (years) & & \multirow{4}{*}{0.143} \\
\hline $30-39$ & $36.29 \pm 8.36$ & \\
\hline $40-49$ & $37.00 \pm 11.14$ & \\
\hline 50 or more & $32.38 \pm 7.70$ & \\
\hline \multicolumn{2}{|l|}{ Residence } & \multirow{3}{*}{0.269} \\
\hline Rural & $34.41 \pm 9.41$ & \\
\hline Urban & $36.64 \pm 8.88$ & \\
\hline \multicolumn{2}{|l|}{ Educational level } & \multirow{5}{*}{$0.000 *$} \\
\hline Read and write & $28.16 \pm 5.80$ & \\
\hline Primary & $30.25 \pm 6.40$ & \\
\hline Preparatory & $38.91 \pm 8.07$ & \\
\hline Secondary & $40.00 \pm 9.11$ & \\
\hline \multicolumn{2}{|l|}{ Marital status } & \multirow{4}{*}{0.131} \\
\hline Single & $34.08 \pm 10.40$ & \\
\hline Married & $35.88 \pm 8.94$ & \\
\hline Widowed & $23.00 \pm 1.41$ & \\
\hline \multicolumn{2}{|l|}{ Years of experience } & \multirow{5}{*}{$0.017 *$} \\
\hline $5-<10$ & $38.18 \pm 10.26$ & \\
\hline $10-<15$ & $32.15 \pm 7.92$ & \\
\hline $15-<20$ & $41.21 \pm 10.88$ & \\
\hline$\geq 20$ & $34.14 \pm 8.08$ & \\
\hline \multicolumn{2}{|l|}{ First aid training } & \multirow{3}{*}{$0.001 *$} \\
\hline Yes & $46.43 \pm 6.00$ & \\
\hline No & $34.36 \pm 8.82$ & \\
\hline \multicolumn{2}{|l|}{ Previous witness of road accident } & \multirow{3}{*}{0.053} \\
\hline Yes & $35.85 \pm 9.27$ & \\
\hline No & $28.33 \pm 4.63$ & \\
\hline \multicolumn{2}{|l|}{ Previous assisting in RTA } & \multirow{3}{*}{0.868} \\
\hline Yes & $35.71 \pm 9.58$ & \\
\hline No & $36.06 \pm 8.93$ & \\
\hline
\end{tabular}


Table (4): Relationship between car drivers score of practice and their personal characteristics, at Sohag University, (N=87), 2019.

\begin{tabular}{|c|c|c|}
\hline \multirow{2}{*}{ Personal characteristics } & practice score & \multirow{2}{*}{ P-value } \\
\hline & Mean \pm SD & \\
\hline \multicolumn{2}{|l|}{ Age: (years) } & \multirow{4}{*}{0.678} \\
\hline $30-39$ & $10.49 \pm 4.14$ & \\
\hline $40-49$ & $9.58 \pm 4.82$ & \\
\hline 50 or more & $9.85 \pm 3.38$ & \\
\hline \multicolumn{2}{|l|}{ Residence } & \multirow{3}{*}{$0.033^{*}$} \\
\hline Rural & $9.24 \pm 3.35$ & \\
\hline Urban & $11.14 \pm 4.85$ & \\
\hline \multicolumn{2}{|l|}{ Educational level } & \multirow{5}{*}{0.079} \\
\hline Read and write & $8.26 \pm 2.62$ & \\
\hline Primary & $9.25 \pm 3.96$ & \\
\hline Preparatory & $11.26 \pm 4.37$ & \\
\hline Secondary & $10.62 \pm 4.51$ & \\
\hline \multicolumn{2}{|l|}{ Marital status } & \multirow{4}{*}{0.941} \\
\hline Single & $9.67 \pm 4.31$ & \\
\hline Married & $10.07 \pm 4.11$ & \\
\hline Widowed & $10.50 \pm 6.36$ & \\
\hline \multicolumn{2}{|l|}{ Years of experience } & \multirow{5}{*}{0.811} \\
\hline $5-<10$ & $10.27 \pm 4.92$ & \\
\hline $10-<15$ & $9.25 \pm 4.23$ & \\
\hline $15-<20$ & $10.50 \pm 4.57$ & \\
\hline$\geq 20$ & $10.17 \pm 3.80$ & \\
\hline \multicolumn{2}{|l|}{ First aid training } & \multirow{3}{*}{0.057} \\
\hline Yes & $12.86 \pm 3.63$ & \\
\hline No & $9.77 \pm 4.09$ & \\
\hline \multicolumn{2}{|l|}{ Previous witness of road accident } & \multirow{3}{*}{$0.038 *$} \\
\hline Yes & $10.27 \pm 4.09$ & \\
\hline No & $6.67 \pm 3.20$ & \\
\hline \multicolumn{2}{|l|}{ Previous assisting in RTA } & \multirow{3}{*}{0.444} \\
\hline Yes & $10.56 \pm 4.14$ & \\
\hline No & $9.85 \pm 4.04$ & \\
\hline
\end{tabular}

Table (1): Shows the distribution of the car drivers, according to their personal characteristics. It was found that, $(40.2 \%)$ of drivers their age younger than 40 years with mean \pm SD (Range) $43.36 \pm 9.48(28.0$ $59.0)$. (58.6\%) of them lived in rural areas. (33.3\%) of them had secondary education. $(83.9 \%)$ of them were married and $(59.3 \%)$ of them was Previous assisting in road traffic accident victims

Figure (1): Demonstrated that the knowledge level of car drivers regarding first aid of road traffic accident. $(86 \%)$ of them were unsatisfactory knowledge and 14 $\%$ were satisfactory knowledge.

Table (2) : Illustrated that practical level of the car drivers regarding first aid of road traffic accident. All of them had unsatisfactory practice of first aid about road traffic accident.

Figure (2): Shows that there was asignificant positive correlation between the total score of knowledge and total score of performance of car derivers regrading first aid of road traffic accidents, $\mathrm{r}=(0.446)$ and $\mathrm{P}=(0.000)$.

Table (3): Illustrates that there is a statistical significant difference between total levels of knowledge and personal characteristics regarding to educational level, years of experience and first aid training at $\mathrm{P}=(0.00,0.017 \& 0.001)$ respectively.

Table (4): Demonstrates that there is a statistical significant difference between level of performance and personal characteristic regarding to residence and Previous witness of a road accident at $\mathrm{P}=(0.033$ $\& 0.038$ ) respectively.

\section{Discussion}

Road traffic injuries are a major community health problem that causes severe injuries with increasing deaths each year.. In Egypt, road traffic injuries are a 
significant cause of morbidity and mortality; they are the sixth leading cause of death forming $11.07 \%$ of injuries and $3.85 \%$ of causes of death, and they account for at least one-quarter of all outpatient visits. (EL-Sharkasy et al., 2015, National Center for Biotechnology Information NCBI, 2019).

Aim of study assess knowledge and practices of cardrivers regarding to first aid of road traffic accidents. Concerning total score of knowledge regarding first aid of road traffic accident, it was found that the majority of the car drivers had unsatisfactory knowledge regarding first aid about road traffic accident . These findings may be explained by lack of education for car drivers in basic emergency police and dealing with crises in the roads .

This results agreed with Midani et al., (2019) who condected study in the United Arab Emirates about Knowledge and attitude toward first aid and found that more than half of the population $(54.2 \%)$ had poor knowledge of basic first aid. Also, the current study supported by El-sharkasy et al., (2015) who conducted the study in Port Said- egypt about Impact of First Aid Training Program for Car Drivers about Road Traffic Injuries . They found lack of satisfactory knowledge in relation to first aid measures .

This result, in contrast with Olumide et al., (2015) in South West Nigeria about " Effect of first aid education on first aid knowledge and skills of commercial drivers " and reported that knowledge scores of drivers were $48.9 \%$ unsatisfactory in pretest.

Regarding their total score of performance for first aid about road traffic accident, the current study observed that all car drivers had unsatisfactory performance due to egypt traffic law does not obligate all cars-drivers to take different types of training as well as first aid training before obtaining a license of driving and sohag university does not obligate car drivers to take first aid training before getting a driver job.

This results agree with El-sayed et al., (2018) who reported that total practices score of drivers preprogram implementation less than one fifth of them had satisfactory practices. This finding was in contrast with Olumide et al., (2015). They reported that score of first aid skill for intervention drivers were $17.5 \%$ pre intervention. Also, The current study supported by El-sharkasy et al., (2015) found that $99 \%$ of the car drivers were unsatisfied performance level.

Concerning the correlation between knowledge and performance score, the current study shows that a positive significant correlation between the knowledge and performance score.

This reults agree with El-sayed et al., (2018) reported that there was a positive correlation between total knowledge and total practices score pre program implementation. This finding was in agreement with Galindo et al., (2017) who conducted the study in Brazil about " Health education interventions on first aid measures for lay people: integrative review" and reported that there was an association between the performance and knowledge for the study participants.

Also, the current study supported by El-sharkasy et al., (2015). they found that there was correlation between first aid knowledge, first aid measures and observed practice in pre-tests. Also, Teshale et al., (2017) who conducted the study in Addis Ababa, Ethiopia about Knowledge, Attitude and Practice of first aid and factors associated with practice among taxi drivers .they found that asignificant positive correlation between the score of knowledge and score of practice of first aid and factors associated with practice among taxi drivers $\mathrm{r}=0.350 \mathrm{p}=(0.05)$

Acorrding to relationship between car drivers total score of knowledge and personal characteristics, the current study illustrates that there is a statistical significant difference between total levels of knowledge and personal characteristics regarding to educational level, years of experience and first aid training at $\mathrm{P}=(0.00,0.017 \& 0.001)$ respectively.

This results agree with El-sharkasy et al., (2015) who revealed that there were statistically significant relations preprogram implementation between drivers' total knowledge score and care driver education, numbers of previous training. The current study, also , supported by El-sayed et al., (2018). They reported that there were statistically significant relations preprogram implementation between drivers' total knowledge score and years of experience.

These results are congruent with Larsson et al., (2002) who conducted the study in Nigeria about First Aid Training and Bystander Action at Traffic Crashes-A Population Study, who stated that higher levels of education were more willing to participate in first aid training which might be related to generally more positive attitude towards education.

In the same line with Adelborg et al., (2011) who conducted the study in turkey about Benefits and Shortcomings of man-datory first aid and basic life support courses for leaner drivers. they found that the person exposed to the training program had higher knowledge scores than those with no exposure to training programs.

Concering their relationship between car drivers performance score and personal characteristics. there is a statistical significant difference between level of performance and personal characteristic with residence and Previous witness of a road accident at $\mathrm{P}=(0.033 \& 0.038)$ respectively. 
Performance level was increased with urban drivers because urban community which characterized by higher levels of exposure of urban drivers to health related knowledge and practices, the availability of first aid training opportunities for drivers, increased cultural awareness of first aid, population overcrowding and increased transportation which leads to increased road accidents .Performance level was increased with Previous witness of a road accident because of increasing the witness of accidents leads to increased driver motivation to seek first aid training .

\section{Conclusion}

The current study concluded that there were a lack of knowledge and appropriate practices regarding first aid of road traffic accident

\section{Recommendation: The study recommended that}

1- Establishing training program for car drivers regarding first aid of road traffic accidents.

2- Make the first aid training program compulsory before getting driving licenses. This training should be continuous and repeated before every renewal of the driving license, and refresher courses for professional drivers should be every year at the maximum.

3- Obligates car drivers to take first aid training before getting a driver job, and refresher course for drivers should be every year and free by Sohag University.

\section{Reference}

1. Adenike, I., Olugbenga-Bello, Oluwadiya, K., Sunday, Bret, A., Nicks, Olakulehin A., Olawale, Adewole O., Adefisoye (2012): First aid knowledge and application among commercial inter-city drivers in Nigeria. African Journal of Emergency Medicine, V (2),N(108).

2. Awasthi S., Pamei G., Solanki H., Kaur A., \& Bhatt M., (2019): Knowledge, attitude, and practice of first aid among the commercial drivers in the Kumaon region of India. J Family Med Prim Care. V(8),N(6)

3. Baburao B., \& Gbadamosi S., (2016), Epidemiological study of road raffic accident cases visiting the emergency department of the Osmania general hospital, Hyderabad, Telangana, India, International Journal of Community Medicine and Public Health, V(3),N(4)

4. Centers For Diseases Control and Prevention, (CDCP), (2017): Injury prevention, available at https://wwwnc.cdc.gov accessed at November 17,2017

5. Central agency for puplic moblization and statistics, ( capmas),(2019): road traffic accident, avilable at https://www.capmas.gov .eg accessed at 2019

6. El-sayed D., Abd El-Megeed H., Abd El Hameed H., \& Abd El-rahman B., (2018): First Aid Training Program for Drivers regarding Road Traffic Injuries in Benha submitted in partial fulfillment of the requirment for the doctorate degree in community health nursing faculty of nursing, Benha university.

7. EL-Sharkasy, M., Shenouda, M., EL-Sheikh, E., Gida, N., \& El-Shahat, M., (2015): Impact of First Aid Training Program for Car Drivers about Road Traffic Injuries in Port Said, Med. J. Cairo Univ.,V(83),N(2)

8. Galindo, N., Vasconcelos, E., Silva, T., Santos, A., \& Mesquita, K., (2017): Health Education Interventions on First Aid Measures for Lay People in Brazil: Integrative Review, Cienc Cuid Saude ; V(16),N(4)

9. Gupta S., Monga S., Paul R., Dhingra R., Arora H., \& Kaur H., (2014): A Study of Antecedent Factors influencing the Road Traffic Accidents in Malwa Region of Punjab, J Adv MED Dent Scie, V (2), N (4)

10. Karyś J., Rębak D., Karyś T., KowalczykSroka B., Maćkowski M., (2015): Knowledge of first aid in road traffic accidents among drivers from the Staszów County. Archives of Physiotherapy and Global Researches, 19(1):2933.

11. Khader Y., Assabri A., \& Alfalahi E., (2017): Pattern of road traffic injuries in Yemen: a hospital-based study, The Pan African Medical Journal, Vol(1),N(1)

12. Kussia A., (2017): Trends, Causes, and Costs of Road Traffic Accidents in Ethiopia, First editions, GRIN Verlag, P.P 1-9

13. Larsson E., Martensson N., \& Alex-Anderson K., (2002): First Aid Training and Bystander Action at Traffic Crashes-A Population Study. Pre-hospital and Disaster Medicine, V(17),N (3)

14. Magruder K., Adams N., Thoresen S., \& Olff M., (2016): Prevention and public health approaches to trauma and traumatic stress: a rationale and a call to action, Eur $\mathbf{J}$ Psychotraumatol., V(7),N(10)

15. Midani O., Tillawi T., Saqer A., Hammami M., Taifour H., Mohammad H., (2019): Knowledge and attitude toward first aid: A cross-sectional study in the United Arab Emirates. Avicenna J Med. V(1),N(7). 
16. National Center for Biotechnology Information, (NCBI), (2019): Road Traffic Injuries, Available at https://www.ncbi.nlm.nih.gov accessed at 2019

17. Olumide, O., Asuzu, C., \& Kale, O., (2015): Effect of First Aid Education on First Aid Knowledge and Skills of Commercial Drivers in South West Nigeria. Prehosp Disaster Med, $\mathrm{V}(30), \mathrm{N}(6)$

18. Stanhope M., \& Lancaster S., (2018): foundations for population health in community/ public health nursing ,fifth edition, Elsevier,P.P338

19. Teshale A., \& Alemu Z., (2017): Knowledge, Attitude and Practice of first aid and factors associated with practice among taxi drivers in Addis Ababa, Ethiopia, Ethiop. J. Health Dev , $\mathrm{V}(31), \mathrm{N}(3)$

20. World Health Organization,(WHO),(2016): The burden of road traffic crashes, injuries and deaths in Africa: a systematic review and metaanalysis, Available at http://apps.who.int Accessed at 2016 